\title{
A diagnostic Approach to Deltoid Muscle Masses
}

\author{
A. Iqbal, E. McLoughlin, A. Patel, A.M. Davies, S.L. James, R. Botchu \\ Royal Orthopaedic Hospital NHS Foundation Trust, Birmingham, UK
}

\author{
CORRESPONDING AUTHOR: \\ Rajesh Botchu \\ Department of Musculoskeletal Radiology \\ The Royal Orthopedic Hospital \\ Bristol Road South \\ Northfield, Birmingham, UK \\ Phone: 00441216854000 \\ E-mail: drbrajesh@yahoo.com \\ DOI: \\ 10.32098/mltj.04.2019.16
}

LEVEL OF EVIDENCE: 4

\begin{abstract}
SUMMARY
Introduction. Referred pain along the deltoid muscle is a common presentation of patients with shoulder pathology. Intramuscular lesions involving the deltoid muscle are often identified on routine ultrasound or magnetic resonance imaging of the shoulder. The aim of this retrospective study is to review deltoid lesions identified at our institution and to provide a diagnostic approach to aid their management.

Methods. A retrospective study of our orthopaedic oncology database was performed to identify lesions referred to our institution between June 2007 and June 2018. Relevant imaging was reviewed on our picture archiving and communication system (PACS). Patient demographics, anatomical extent and MRI characteristics of the lesions were assessed along with histological correlation.

Results. 91 patients were included in the study of which $42(46 \%)$ were male and 49 $(54 \%)$ were female with an age range of $22-88$ years. 8 patients were under 40 years and one low grade fibromyxoid sarcoma was identified in this age group. In the over 40 year cohort, the commonest lesion was a lipoma and malignant lesion was identified in $13(16 \%)$ patients. The vast majority of lesions were confined to a single deltoid muscle compartment. 4 lesions involved more than one compartment, all of which were malignant.

Conclusions. Deltoid lesions in patients under 40 years are highly likely to be benign whereas the probability of malignancy increases in patients over 40 years of age. Lesions involving more than one muscle compartment are likely to be malignant.
\end{abstract}

\section{KEY WORDS}

deltoid; mass; tumour

\section{INTRODUCTION}

Patients with shoulder pathology often present with referred pain along the deltoid muscle or at its insertion onto the deltoid tuberosity of the humerus (1). The common pathologies arising around the shoulder have been extensively documented in the literature, however, there is limited content regarding pathology of deltoid muscle origin.

Pathologies involving the deltoid muscle are an uncommon but important cause of shoulder pain and may manifest as enlargement of the muscle belly or a symptomatic reduction in shoulder movement. These include calcific tendinitis, traumatic, inflammatory and neoplastic conditions (2). Denervation of the deltoid muscle is seen in pathologies and traumatic injuries to the axillary nerve, quadrilateral space and Parsonage-Turner syndromes $(3,4)$. Soft tissue lesions within the deltoid muscle are often identified on routine Ultrasound (US) or Magnetic Resonance Imaging (MRI) performed for common shoulder pathologies such as rotator cuff tears or subacromial subdeltoid bursitis.

In our tertiary orthopaedic oncology centre, we encounter many deltoid lesions in patients presenting with shoulder pain. The aim of this retrospective study is to review the deltoid lesions we have identified and to provide a diagnostic approach to aid the management of these lesions.

Anatomically the deltoid muscle is made up of three sets of fibres (heads) termed the anterior (clavicular), middle (acromial) and posterior (scapula) fibres (figure 1).

The anterior fibres arise from the anterior border and superior surface of the lateral third of the clavicle (9). The lateral fibres arise from the superior surface of the acromion and the posterior fibres arise from the inferior lip of the posterior border of the scapula. The muscle fibres converge to insert onto the deltoid tuberosity located on the middle and lateral aspect of the shaft of the humerus (10). 


\section{MATERIALS AND METHODS}

We performed a retrospective study of our orthopaedic oncology database to identify all patients with an intrinsic deltoid mass lesion referred to our institution between June 2007 and June 2018.

The relevant imaging of these patients was reviewed on our picture archiving and communication system (PACS) by an experienced MSK radiologist and musculoskeletal radiology fellow.

The demographics of our patient cohort and the anatomical extent and characteristic MRI appearances of the deltoid lesions were assessed.

Histological confirmation was obtained from US guided biopsy, tru-cut biopsy or following excision. Only intrinsic deltoid muscle lesions were included in the study. Paediatric patients with deltoid lesions were excluded from the study as these lesions behave differently to lesions within adults.

\section{RESULTS}

\section{Demographics}

A total of 134 patients with deltoid lesions were identified on the oncology database. 43 patients were excluded from the study after exclusion criteria (see above) were applied. Of the remaining 91 patients, $42(46 \%)$ were male and 49 $(54 \%)$ were female. The age range was $22-88$ years with a mean age of 58.7 years. Benign lesions were identified in $84 \%$ of patients whilst $16 \%$ of lesions were malignant.

The cohort was divided into two subgroups by age (i.e $>/<$ 40 years). In the over 40 group, 82 lesions were identified of which 69 lesions $(84 \%)$ were benign and 13 lesions (16\%) were malignant (figure 2). In the under 40 group, 8 lesions were identified of which $7(88 \%)$ were benign and $1(12 \%)$ was malignant (figure 2). The malignant lesion was a low grade fibromyxoid sarcoma in a 22 -year old male.

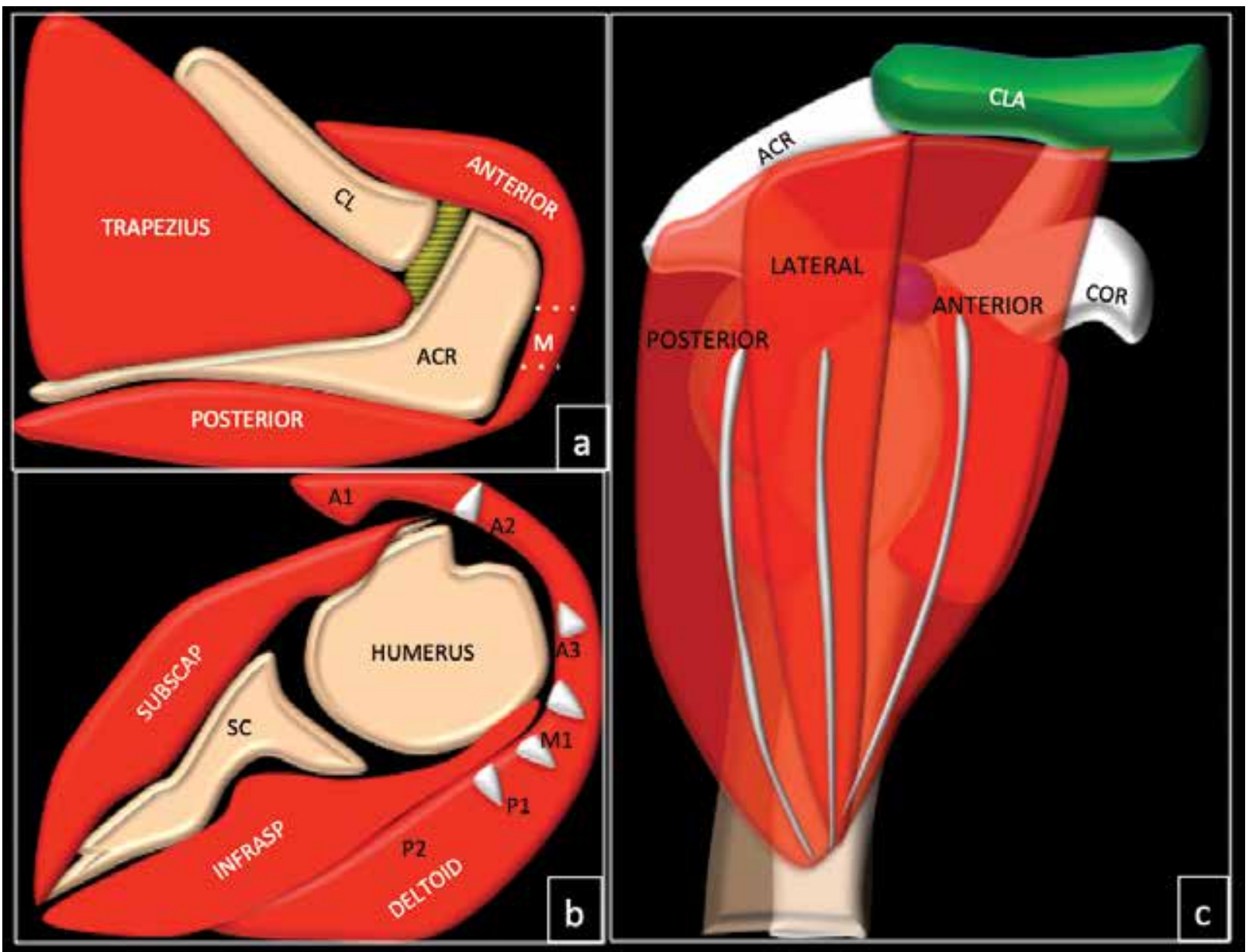

Figure 1. Diagrammatic representation axial (a and b) and sagittal (c) showing difference part of the deltoid. A- anterior, MMiddle, P-posterior, CL- clavicle, ACR- acromion, SC-scapula. 
Overall $47 \%$ of lesions were in male patients whilst $53 \%$ of lesions were in female patients.

\section{Anatomical extent}

In our study, a total of 88 cases $(96 \%)$ had a deltoid lesion which was confined to a single head (set of fibres). Only 4 $(4 \%)$ patients had lesions which involved more than one set of muscle fibres (heads) all of which were malignant and included two soft tissue sarcomas, one metastatic lesion and one B cell non-Hodgkin's lymphoma (figure 3).

\section{Biopsy}

In our centre, 47 out of a total 91 deltoid muscle lesions were identified as intramuscular lipomas radiologically and did not undergo a histological diagnosis.

Of the remaining 44 cases, 41 lesions (95\%) underwent histological diagnosis. Of the 41 lesions that underwent biopsy, 26 lesions (63\%) were benign. 15 lesions (37\%) were malignant.

\section{Lesion type}

Overall, the commonest lesion was a benign lipoma identified in 47 cases $(52 \%)$ of which 46 were found in the over 40 group. A traumatic haematoma was identified in 1 elderly patient ( $1 \%$ ) following a fall (figure 4 ).

The different benign and malignant lesions encountered are shown in table I and table II. (figure 5, 6)

\section{DISCUSSION}

Radiological imaging is important in the diagnosis of soft tissue lesions. Although ultrasound and MRI are the main-

Table I. Demonstrating the various malignant lesions encountered in our study.

\begin{tabular}{ll}
\hline Metastases & 3 \\
\hline MPNST & 1 \\
\hline NHL & 2 \\
\hline Synovial sarcoma & 2 \\
\hline High grade pleomorphic sarcoma & 2 \\
\hline High grade pleomorphic spindle cell sarcoma & 2 \\
\hline High grade epithelioid sarcoma & 1 \\
\hline Fibromyxoid sarcoma & 1 \\
\hline High grade myxofibrosarcoma & 1 \\
\hline
\end{tabular}

stay of imaging of soft tissue lesions, radiographs play an important role in assessing features such as distortion of soft tissue planes, foreign bodies, soft tissue calcifications and remodelling of adjacent bone (22).

USS and MRI are able to distinguish many benign and aggressive features and are both sensitive and specific for diagnosing many lesions such as lipomas and vascular malformations. However, there are a further group of lesions that imaging alone is unable to accurately diagnose (22). The gold standard is to provide the pathologists with tissue either by image guided biopsy, open biopsy or surgical excision. Imaging findings along with radiological diagnosis are vital to the pathologist as aids to address the histological findings.

\section{Benign lesions}

Many of the benign intramuscular lesions in our study have characteristic MRI features. These lesions include lipoma, atypical lipomatous tumour (ALT), arteriovenous malformation (AVM), haemangioma, myxoma and schwannoma. Lipoma is the commonest intramuscular lesion and accounted for $50 \%$ of the cases in our study (table II). The MRI features of these lesions are equivalent to those of adipose tissue (hyperintensity on T1W, hyperintensity on T2W and homogenous suppression on fat suppression sequences $(11,12)$.

The clinical diagnosis of intramuscular benign peripheral nerve sheath tumour (BPNST) is difficult as deeper lesions do not demonstrate the typical clinical signs such as positive tinel's test as they arise from small motor nerve branches within the muscle substance (13). These lesions are often ovoid hyperintense lesions on fluid sensitive sequences with central low intensity, the target sign (14). The fat split sign, where a rim of fat is seen surrounding the lesion is sensi-

Table II. Table demonstrating the various benign lesions identified in our study.

\begin{tabular}{ll}
\hline Fibromatosis & 3 \\
\hline Vascular Malformation & 4 \\
\hline Myxoma & 8 \\
\hline Lipoma & 47 \\
\hline ALT & 4 \\
\hline Nodular fasciitis & 2 \\
\hline Myofibroblastoma/myofibroma & 1 \\
\hline Schwannoma & 4 \\
\hline Haemangioma & 2 \\
\hline Haematoma & 1 \\
\hline
\end{tabular}

Muscles, Ligaments and Tendons Journal 2019;9 (4) 


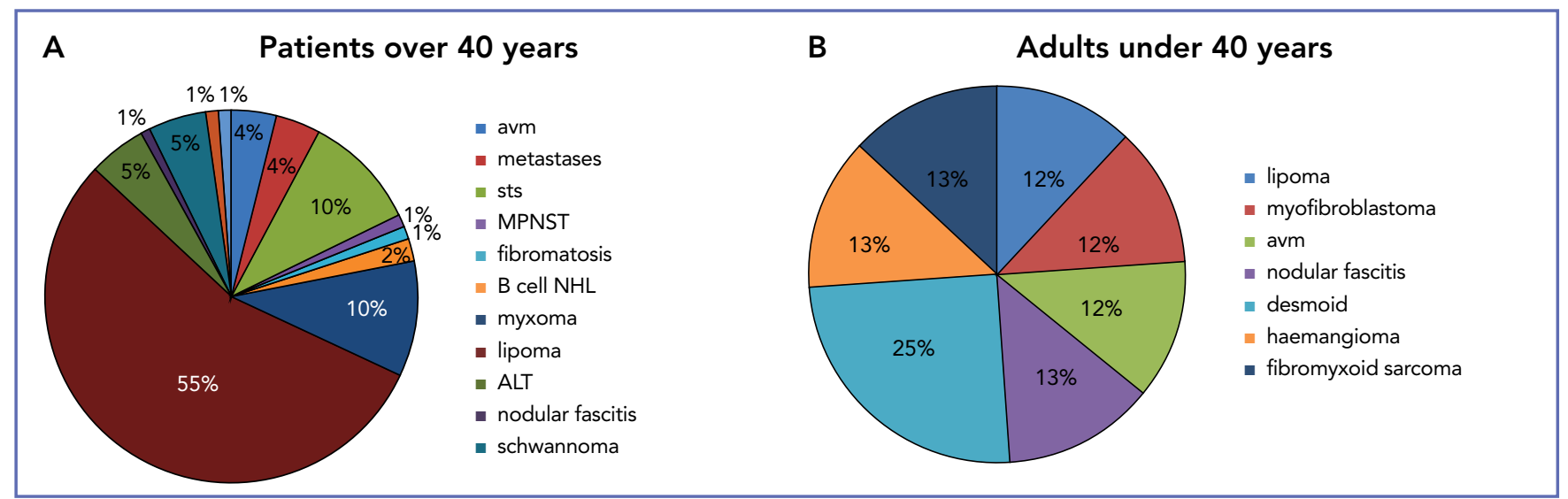

Figure 2. Pie chart (a) demonstrating the various lesions occurring in patients under 40 years. Pie chart (b) demonstrating the various lesions occurring in patients under 40 years.

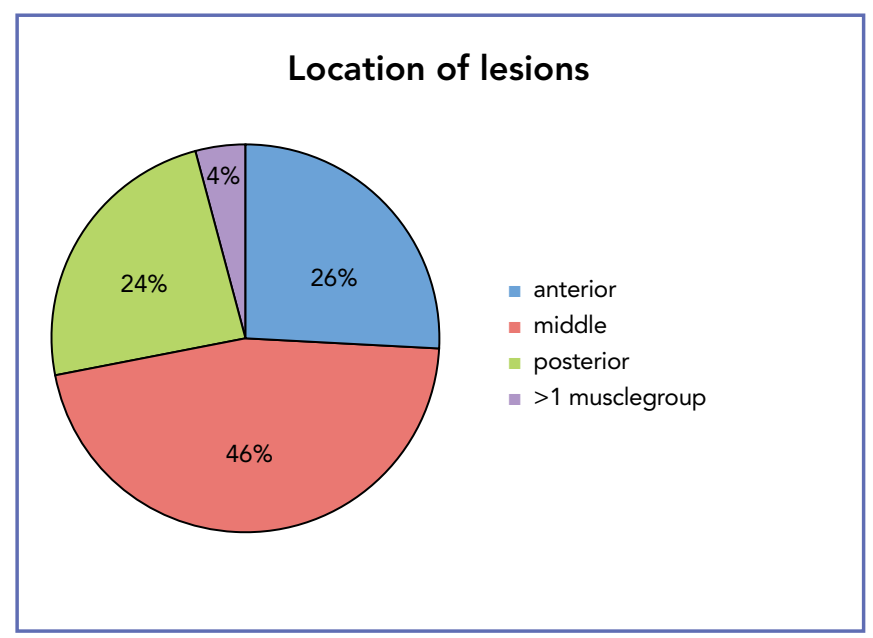

Figure 3. Pie chart demonstrating the distribution of lesions within the deltoid muscle.

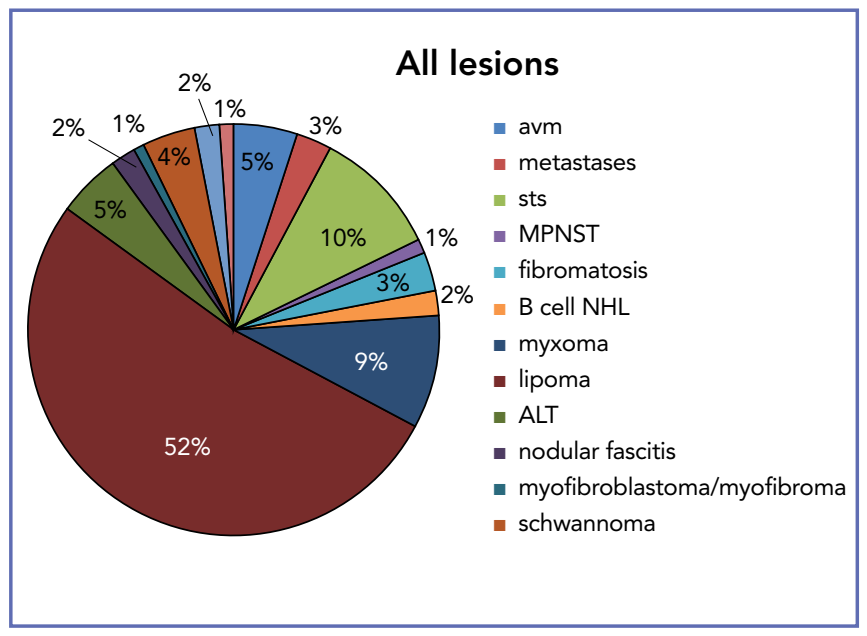

Figure 4. Pie chart demonstrating the percentage of all lesions encountered in our study.

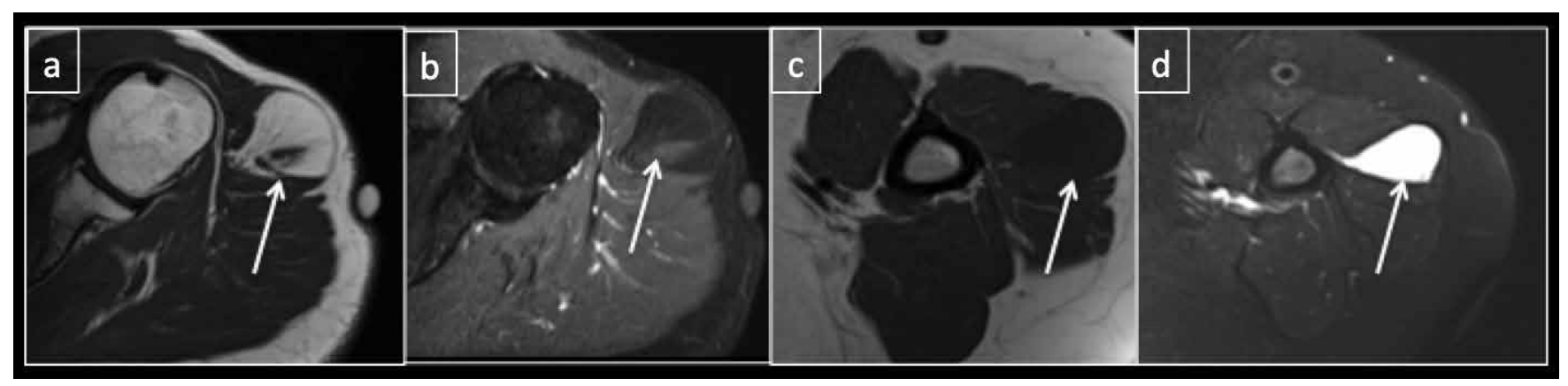

Figure 5. Axial T1(a) and STIR(b) showing a lipoma (arrow) within the anterior fibres of the deltoid in a 35 year old male. Axial $\mathrm{T} 1$ (c) and STIR(d) showing a myxoma (arrow) within the anterior fibres of the deltoid in a 40 year old female. 


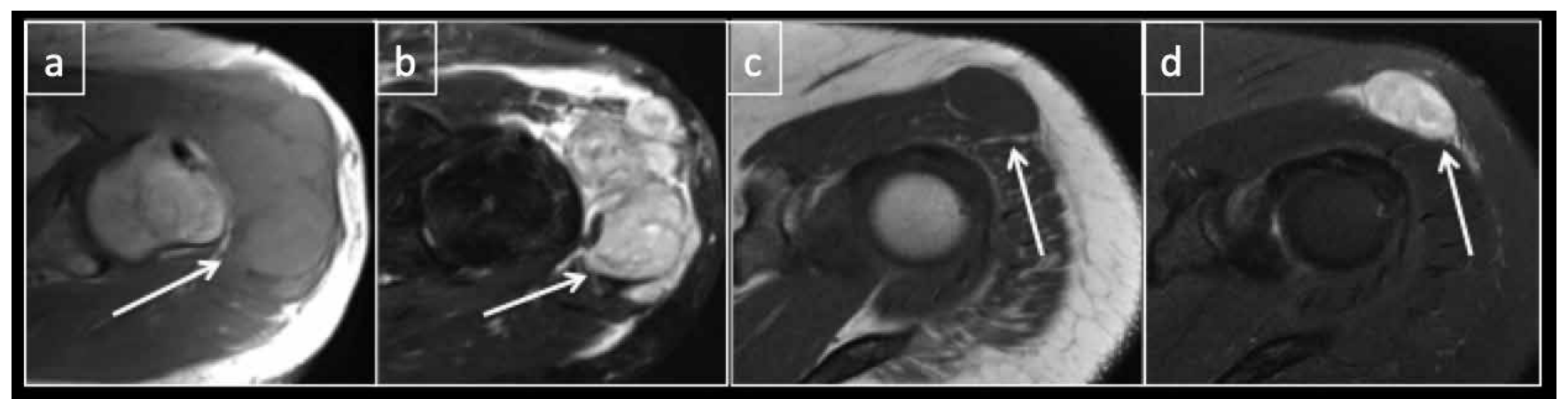

Figure 6. Axial T1(a) and STIR(b) showing large tumour (arrow) involving the anterior and middle fibres of the deltoid- biopsy proven renal cell carcinoma metastasis in a 60-year-old male. Axial T1(c) and STIR(d) showing a tumour (arrow) within the anterior fibres of the deltoid - biopsy proven pleomorphic sarcoma in a 45-year-old male.

tive and specific for BPNST and is best appreciated on T1 weighted sequences (15). Multiple ring-like structures within the lesion with peripheral increased signal on fluid sensitive sequences is known as the fascicular sign (15).

Arterio-venous malformations are masses containing vessels which appear as flow voids on MR sequences interposed with fat (16). The presence of low T1/T2 signal calcified phleboliths is a sensitive sign which aid in the diagnosis of these lesions (17).

Intramuscular myxomas commonly affect the upper extremities, thighs and gluteal region (18). They are often solitary, however, multiple lesions are seen in syndromes such as Mazabrauds which consists of polyostotic fibrous dysplasia and multiple intramuscular myxomas. The lesions are hypointense on T1 and hyperintense on T2 weighted sequences (19).

Intramuscular haemangiomas are common in the general population. The lesions demonstrate increased $\mathrm{T} 1$ signal due to fat content with focal areas of low signal due to fibrous tissue, thrombi or phleboliths. On fluid sensitive MR sequences, the lesions are also of increased signal relative to muscle and typically have a tubular 'bag of worms' appearance with focal areas of low signal (20). The lesion has indistinct borders.

\section{Malignant lesions}

Malignant soft tissue lesions display features such as aggressive growth, intra-lesional haemorrhage, necrosis, invasion or displacement of local structures such as nerves and blood vessels and adjacent the musculature (21).

A number of malignant lesions were identified in our patient cohort including nine soft tissue sarcomas (STS) of varying histological (table I), three metastatic soft tissue lesions (large cell lung $\mathrm{Ca}$, breast $\mathrm{Ca}$, and Renal cell $\mathrm{Ca}$ ), a malignant peripheral nerve sheath tumour in a patient with neurofibromatosis type 1 and two cases of B Cell non-Hodgkin's lymphoma.

\section{Learning points}

Analysis of our data set has highlighted several points which aid the clinician in the management of patients with intramuscular deltoid lesions (24).

The likelihood of a malignant deltoid lesion in a patient under 40 years is low (12\%). Therefore, provided that there are no aggressive features, these patients do not require urgent referral to a soft tissue sarcoma centre for histological diagnosis. A routine ultrasound may be performed to aid in the diagnosis.

The likelihood of a malignant deltoid lesion in a patient over 40 years is higher. Therefore, all non-lipomatous lesions will require histological diagnosis. For confirmed malignant lesions, a staging CT thorax, abdomen and pelvis should be performed.

Lesions involving more than one set of deltoid muscle fibres (heads) are likely to be malignant and should undergo urgent biopsy and staging CT thorax, abdomen and pelvis.

\section{CONCLUSIONS}

Our study is the largest in the literature assessing intrinsic deltoid muscle masses. This study provides a diagnostic approach to deltoid lesions for clinicians who encounter these lesions on routine MRI of the shoulder or upper arm in patients presenting with shoulder pain.

Deltoid lesions in patients under 40 years are highly likely to be benign whereas the probability of malignancy increas- 
es in patients over 40-years and all non-lipomatous lesions in this cohort should be referred for histological diagnosis. The likelihood of a malignant lesion is also increased in lesions involving more than one set of deltoid muscle fibres (heads) and a histological diagnosis and staging computed tomography (CT) should be performed in these patients.

\section{REFERENCES}

1. Bayam L, Ahmad MA, Naqui SZ, Chouhan A, Funk L. Pain Mapping for Common Shoulder Disorders. Am J Orthop. 2011 July;40(7):353-358

2. Moser T, Lecours J, Michaud J, Bureau NJ, Guillin R, Cardinal E. The deltoid, a forgotten muscle of the shoulder. Skeletal Radiology. October 2013, Volume 42, Issue 10, pp 1361-1375

3. Linker CS, Helms CA, Fritz RC. Quadrilateral space syndrome: findings at MR imaging. Radiology. 1993;188(3):675-6.

4. Gaskin CM, Helms CA. Parsonage-Turner syndrome: MR imaging findings and clinical information of 27 patients. Radiology. 2006;240(2):501-7.

5. Ilaslan H, Iannotti JP, Recht MP. Deltoid muscle and tendon tears in patients with chronic rotator cuff tears. Skeletal Radiol. 2007;36(6):503-7.

6. Morisawa K, Yamashita K, Asami A, Nishikawa H, Watanabe H. Spontaneous rupture of the deltoid muscle associated with massive tearing of the rotator cuff. J Shoulder Elbow Surg. 1997;6(6):556-8

7. Flores DV, Gómez CM, Estrada-Castrillón M, Smitaman E, Pathria MN. MR Imaging of Muscle Trauma: Anatomy, Biomechanics, Pathophysiology, and Imaging Appearance. Radiographics 38(1):170072 - December 2017

8. Donnelly LF, Helms CA, Bisset GS. Chronic Avulsive Injury of the Deltoid Insertion in Adolescents: Imaging Findings in Three Cases. RSNA. Published Online:Apr 1 1999. Availabe from: https://doi.org/10.1148/radiology.211.1.r99mr03233

9. Kumar VP, Satku K, Liu J, Shen Y. The anatomy of the anterior origin of the deltoid. J Bone Joint Surg Br. 1997;79(4):680-3

10. Morgan SJ, Furry K, Parekh AA, Agudelo JF, Smith WR. The deltoid muscle: an anatomic description of the insertion to the proximal humerus. J Orthop Trauma 2006;20:19-21.

11. Gupta P, Potti TA, Wuertzer SD, Lenchik L, Pacholke DA. Spectrum of Fat-containing Soft- Tissue Masses at MR Imaging: The Common, the Uncommon, the Characteristic, and the Some- times Confusing. RadioGraphics 2016; 36:753-766

12. McTighe S, Chernev I. Intramuscular lipoma: a review of the literature. Orthop Rev (Pavia). 2014 Oct 27; 6(4): 5618. Orthopedic Reviews 2014; volume 6:5618

13. Salunke AA, Chen Y, Tan JH, Chen X, Foo TL, Gartner LE, Puhaindran ME. Intramuscular schwannoma: clinical and magnetic resonance imaging features. Singapore Med J 2015; 56(10): 555-557 doi: 10.11622/smedj.2015151

14. Kakkar C, Shetty CM, Koteshwara P, Bajpai S. Telltale signs of peripheral neurogenic tumors on magnetic resonance imaging. Indian J Radiol Imaging. 2015 Oct-Dec; 25(4): 453-458.

15. Murphy MD, Smith WS, Smith SE, Kransdorf MJ, Temple HT. From the archives of AFIP. Imaging of muskuoskeletal neurogenic tumors: radiological-pathological correation. Radiographics. 1999;19(5):1253-80.

16. Flors L, Leiva-Salinas C, Maged IM, Norton PT, Matsumoto AH, Angle JF, Bonatti MDH, Park AW, Ahmad EA, Bozlar U, Housseini AM, Huerta TE, Hagspiel KD. MR Imaging of Soft-Tissue Vascular Malformations: Diagnosis, Classification, and Therapy Follow-up. Eur J Radiol. 2010 Jul;75(1):2-11. doi: 10.1016/j.ejrad.2010.04.009.

17. Ernemann U, Kramer U, Miller S, Bisdas S, Rebmann $\mathrm{H}$, Breuninger $\mathrm{H}$, Zwick C, Hoffmann J.

18. Current concepts in the classification, diagnosis and treatment of vascular anomalies. Eur J Radiol 2010;75(1):2-11.

19. Granel-Villach L, Alcalde-Sánchez M, Salvador-Marín M, García-Calvo R, Santonja-López N, Salvador-Sanchís JL. Differential diagnosis and management of intramuscular myxomas: A review of our experience. Cir Cir. $2017 \mathrm{Jul}$ Aug;85(4):356-360.

20. Murphey MD, McRae GA, Fanburg-Smith JC, Temple HT, Levine AM, Aboufalia AJ. Imaging of soft-tissue myxoma with emphasis on CT and MR and comparison of radiologic and pathologic findings. Radiology, 225 (2002), pp. 215-224

21. Wierzbicki JM, Henderson JH, Scarborough MT, Bush CH, Reith JD, Clugston JR. Intramuscular Hemangiomas. SAGE Journals. Vol 5, Issue 5, 2013

22. Chan PW. imaging of soft tumors of the extremities: a practical approach. World J Radiol. 2013 Dec 28; 5(12): 455-459.

23. Wu JS, Hochman MG. Soft-Tissue Tumors and Tumorlike Lesions: A Systematic Imaging Approach. Radiology. 2009 Nov;253(2):297-316.23) Enzinger FM, Weiss SW. Soft Tissue Tumors, 2nd ed. St. Louis: CV Mosby, 1988:2.

24. Padulo J, Oliva F, Frizziero A, Maffulli N. Muscles, Ligaments and Tendons Journal - Basic principles and recommendations in clinical and field Science Research: 2018 update. MLTJ 2018; 8(3): $305-307$. 